\title{
Scale-Heterogeneity of Stock Price Volatility: Evidence from Listed Companies of Real Estate Industry in China
}

\author{
Yu Zhang \\ Business School, Hunan University, Changsha 410082, China. \\ y1997107@163.com
}

\begin{abstract}
To explore the features of stock price volatility in real estate industry under the scale heterogeneity, we use GARCH, TGARCH and EGARCH models to analyze the stock volatility of large- and small-scale real estate firms in China, and compare their results with the Shanghai Composite Index $(\mathrm{SHCl})$. The empirical results show that all three returns for large- and small-scale real estate firms and $\mathrm{SHCl}$ have heteroscedasticity, volatility persistence and asymmetry. Besides, the return series of Shanghai Composite Index exerts a negative leverage effect, while the leverage effect for larger- and small-scale real estate companies shows positive.
\end{abstract}

Keywords: Real Estate Company, scale heterogeneity, stock price volatility, HP wave filtering, GARCH model.

\section{Introduction}

As a very important part of the development of China's national economy, real estate industry plays a significant role in social harmony. According to statistical data, the average growth rate of China's GNP during the period from 2005 to 2014 was $9.993 \%$, of which the average value of added value created by the real estate industry to the GNP was 5.35\%. From 2006 to 2014, the average number of employees in the real estate industry were 461,3000, of which 219,380 were urban units, with 433,900 in state-owned units, 83,900 in collective units and 19,200,00 in other units. Thus it could be seen that the real estate industry was crucial to the economic development and social harmony and stability of China (Chen, 2017).

Financial asset price, as an important indicator to describe the efficiency of financial market, is an important factor that needs to be considered in the process of investment decisions and risk management (Cao, 2008). The real estate industry has occupied an important position in the economic development of China. Because of the high return rate and risk in the real estate industry, our research here analyzing the features of stock volatility in the real estate market, on the one hand, can guide investors and policy-makers to have a clearer understanding of the risks of the industry and make the correct decisions. On the other hand, it also provides a theoretical basis for studying the corresponding hedge plans, so as to promote the healthy and stable development of the real estate market, rationally optimize the allocation of resources, and achieve sustained and stable development of the national economy. In other words, the volatility of the stock price in the real estate industry has an important impact on the entire national economy and even the financial market.

Based on economic fluctuation theory, normative analysis and empirical research have been combined in this article. First, we review related literature about the research progress of the features of stock price volatility. Second, we innovatively analyze the stock price volatility in real estate industry Combining with the stock prices of the real estate industry, we conclude that the stock price of the real estate industry has the ARCH effect is drawn. Third, GARCH model is used to analyze the features of stock price volatility of the real estate industry in China from February 2010 to February 2018 by conducting empirical analysis. Finally, we draw conclusions.

In the empirical research, first of all, the original data are collected and sorted out; the model methods are then described. Next, the model is used to study the real estate and stock price data. Under the premise of testing the ARCH effect, GARCH modeling is performed. Finally, the author summarizes and analyzes the empirical test results and puts forward relevant recommendations. 


\section{Literature Review}

Volatility is one of the core issues in the study of financial economics. In modern finance theory, volatility is wildly-used to represent risk, which can be measured by the variance of returns. Traditional pricing models of financial products often assume that volatility as a constant does not change over time. However, a large number of empirical studies have shown that the volatility of the price of financial products presents aggregation, that is, larger volatility is often accompanied by larger volatility and smaller volatility is often accompanied by smaller volatility.

The earliest model that can be used to explain and reflect the volatility clustering and conditional heteroscedasticity exhibited by the financial time series is the autoregressive conditional heteroskedasticity model (ARCH model) proposed by Engle (1982). With the assumption of regarding variance as the function of the lagged residual square, Bollerslev (1986) puts forward generalized autoregressive conditional heteroskedasticity model (GARCH model), which explained the volatility clustering and conditional heteroscedasticity of financial time series more succinctly. To distinguish the influence of positive and negative impulse on volatility, Zairian (1990) introduce a dummy variable as a threshold on the basis of the GARCH model, and propose a threshold ARCH model (TARCH model), which can effectively describe the asymmetric effect of the volatility. A similar model of reflecting the asymmetric effect of the volatility, Nelson (1991) define the conditional variance as a pair and put forward an exponential ARCH model (EGARCH model).

Some scholars (Jiang and Wang, 2008; Chen, 2015; Shan, 2015; Yu, 2015; Liang, 2016, Jiang and Xing, 2017) study the price and return behavior of China's stock market, and find that China's stock market is similar to Western countries' with its volatility showing obvious features, such as shark peak and heavy tail, heteroskedasticity, and volatility clustering. All these features show that China's stock market has a very obvious ARCH effect.

There are many previous studies on the features of stock price volatility. Most of them are to study the general features of stock price volatility in China, but few people analyze the features of stock price volatility in some specific industries. Due to inequality economic development in various industries in China, investors also have different investment ways. For example, Chen (2015), Goo (2015), Su and Ma (2015) and Lu (2017) respectively investigate the stock price volatility of listed companies in the agricultural industry, the medicine industry, the IT industry, and the banking industry. Analysis of stock volatility features based on different industries can indeed help us to see the differences in risk in different industries and to formulate risk aversion strategies. In view of the high-risk nature of the real estate industry, this article goes deep into the industry, uses the GARCH, TGARCH, and EGARCH models to classify the stock price volatility in the real estate industry in China and compares it with the Shanghai Composite Index.

\section{Research Method}

\subsection{Sample Selection and Preprocessing}

Taking into account the availability of relevant data, the sample data used in this article are the daily closing prices (obtained from CSMAR database) of 102 real estate companies from February 22, 2010 to February 22, 2018. The closing prices of the Shanghai Composite Index within the same period is used for comparison. In terms of data preprocessing, the daily closing prices of the 102 listed real estate companies are classified according to their total assets. There are 19 large-scale companies and 83 small-scale companies. By calculating the average values of Shanghai Composite Index, the larger- and small-scale companies, we apply the HP filter method to de-trend the periodicity of the time series data and select trend components as the data basis for the comparative study of stock price volatility features of different types of real estate companies (the trend series has no negative value, and the cyclical sequence is considered to cause price volatility to deviate from reality for some reasons). Standardization is conducted to obtain time series data of trend components of large- and small-scale listed real estate companies as well as Shanghai Composite Index. 
In order to eliminate the non-stationary of the time series, the log-return is used in this article and is defined as follows:

$$
R_{t}=\ln P_{t}-\ln P_{t-1}
$$

Take the logarithm of the trend component of the stock price returns of large- and small-scale listed real estate companies, and Shanghai Composite Index. And the variable description is shown in Table 1.

Table 1. Variable Description

\begin{tabular}{ccc}
\hline Variable Name & Abbreviation & $\begin{array}{c}\text { Successive or discrete } \\
\text { type }\end{array}$ \\
\hline Large-scale real estate companies' stock price return & LN_HPLSS & Discrete type \\
Small-scale real estate companies' stock price return & LN_HPLSS & Discrete type \\
Shanghai securities composite index return & LN_HPZSS & Discrete type \\
\hline
\end{tabular}

\subsection{Model Setup}

In order to more accurately describe the tail features of the time series, Bollerslev (1986) proposed the generalized ARCH model, namely the GARCH (Generalized ARCH) model. A lagged $h_{t}$ term to the equation of conditional variance is added in the GARCH model, which could reflect a more flexible lag structure. It is defined as:

$$
h_{t}=\alpha_{0}+\sum_{i=1}^{q} \alpha_{i} \varepsilon_{t-1}^{2}+\sum_{j=1}^{p} \beta_{j} h_{t-j}
$$

Where $\alpha_{0}>0, \alpha_{i}>0, \beta_{j}>0, \sum_{i=1}^{q} \alpha_{i}+\sum_{j=1}^{p} \beta_{j}<1$.

In GARCH model, the variance of return is considered to be predictable. The conditional variance depends not only on the latest information but also on the previous conditional variance.

In order to study whether the real estate industry's stock returns have a leverage effect (i.e. when the stock price falls or rises at the same rate, the process of falling stock prices is often accompanied by more severe volatility.) The asymmetric GARCH model can be used. The general asymmetric models include TGARCH model and EGARCH model.

TGARCH (p, q) model is defined as follows:

$$
h_{t}=\alpha_{0}+\sum_{i=1}^{q} \alpha_{i} \varepsilon_{t-1}^{2}+\varphi \varepsilon_{t-1}^{2} I_{t-1}+\sum_{j=1}^{p} \beta_{j} h_{t-j}
$$

$I_{t}$ Is a nominal variable. The rise and fall of $I_{t}$ stock price have different effects on the conditional variance. When it rises, $\varphi \varepsilon_{t-1}^{2} I_{t-1}=0$ and its effect can be represented by coefficient $\sum_{i=1}^{q} \alpha_{i}$. When it falls, coefficient $\sum_{i=1}^{q} \alpha_{i}+\varphi$ is used to represent its effect. If $\varphi \neq 0$, the function of information is asymmetric. If $\varphi>0$, the leverage effect is considered to exist.

$\operatorname{EGARCH}(\mathrm{p}, \mathrm{q})$ model is defined as follows:

$$
\log h_{t}=\alpha_{0}+\sum_{j=1}^{p} \beta_{j} \log \left(h_{t-j}\right)+\sum_{i=1}^{q}\left(\alpha_{i}\left|\frac{\varepsilon_{t-1}}{\sqrt{h_{t-1}}}\right|+\varphi_{i} \frac{\varepsilon_{t-1}}{\sqrt{h_{t-1}}}\right)
$$

If $\varphi \neq 0$, it is can be seen that the function of information is not asymmetric. If $\varphi<0$, the leverage effect is significant.

\section{Empirical Analyses}

\subsection{Descriptive Statistics}

First, we check the basic statistical characteristics of the HP filtered returns of large- and smallscale real estate firms and the SHCI during the sample period. As is shown in Table 2, generally, both 
the means and variances of the two returns are in the neighborhood respectively. Meanwhile, compared with the standard normal distribution with scenes 0 and kurtosis 3 , the skew nesses of both returns here are negative (i.e. left skewed) while kurtoses are far larger than 3 , hence we may deduce that each return has a leptokurtic distribution with a fat left tail. In other words, returns here do not have the standard normal distribution. At the $5 \%$ level of significance, the value of JB statistics is greater than 5.99 at a significant level of 5\%, indicating that the real estate industry's stock price return rate does not obey the normal distribution. On the whole, the real estate industry's stock price return rate has a very distinctive social characteristics of concentration, and can be estimated with the GARCH model.

Table 2. Descriptive statistics

\begin{tabular}{cccccccc}
\hline & Mean & Std. Dev. & Scenes & Kurtosis & $\begin{array}{c}\text { Jarque- } \\
\text { Bera }\end{array}$ & LB-Q(20) & ARCH(20) \\
\hline dln hplss & $\begin{array}{c}- \\
0.000149\end{array}$ & 0.006802 & $\begin{array}{c}0.746948 \\
-\end{array}$ & 5.533207 & 701.2788 & $9001.0^{* * *}$ & $1923.319^{* * *}$ \\
dln_hpsss & 0.000139 & 0.007098 & $\begin{array}{c}2.046081 \\
-\end{array}$ & 14.77548 & 12600.98 & $8973.6^{* * *}$ & $1924.775^{* * *}$ \\
dln_hpzss & $2.48 \mathrm{E}-05$ & 0.004364 & $\begin{array}{c}- \\
1.030551\end{array}$ & 7.913328 & 2301.87 & $9087.6^{* * *}$ & $1923.738^{* * *}$ \\
\hline
\end{tabular}

Notes: $* * *$ Rejection of the null hypothesis at $1 \%$ significance level

\subsection{Empirical Analysis}

\subsubsection{Unit Root Test}

Considering the GARCH-family model's requirement for the stationary of the time series data used, the first step must be to test the stationary of all the time series data used before applying this type of models to performing empirical analysis. This paper uses the ADF test to examine large-scale listed real estate companies, small-scale listed real estate companies, and Shanghai Composite Index data, then finds that the data after the first-order difference is stable. The test results are shown in Table 3. It can be seen that all three indicators are stable and can be used GARCH modeling.

Table 3. ADF Test Results

\begin{tabular}{ccccc}
\hline Series & Test Forms & T Statistics & P Value & Conclusion \\
\hline dln_hplss & $(0,0,0)$ & -10.03529 & 0 & Stable \\
dln_hpsss & $(0,0,0)$ & -10.57271 & 0 & Stable \\
dln_hpzss & $(0,0,0)$ & -9.4232 & 0 & Stable \\
\hline
\end{tabular}

\subsubsection{Impact of External Shock on Stock Price Fluctuations}

Because of the fat tail of the return, the GED distribution is introduced to depict the residual of the GARCH model. According to the requirements that the AIC value should be relatively small, and model coefficients must be significant and positive, the $\operatorname{GARCH}(1,1)$ model is the best when comparison are made among $\operatorname{GARCH}(1,1), \operatorname{GARCH}(1,2), \operatorname{GARCH}(2,1)$ and $\operatorname{GARCH}(2,2)$ models. For series dln_hplss, an ARMA(4,0)-GARCH(1,1) model is singled out for the volatility of stock price return; for series dln_hpsss, an ARMA $(4,4)-\operatorname{GARCH}(1,1)$ model is singled out for the volatility of stock price return; for serise dln_hpzss, an ARMA(4,3)-GARCH(1,1) model is singled out for the volatility of stock price return. All parameter estimation results are stated in Table 4. 
Table 4. Estimation results of GARCH for stock price return

\begin{tabular}{|c|c|c|c|}
\hline Parameter & dln_hplss & dln_hpsss & dln_hpzss \\
\hline \multicolumn{4}{|c|}{ Mean equation } \\
\hline $\operatorname{ar}(1)$ & $\begin{array}{c}3.0844 * * * \\
(0.0203)\end{array}$ & $\begin{array}{c}1.7768 * * * \\
(0.3235)\end{array}$ & $\begin{array}{c}1.6321 * * * \\
(0.0716)\end{array}$ \\
\hline $\operatorname{ar}(2)$ & $\begin{array}{c}-3.6273 * * * \\
(0.0576)\end{array}$ & $\begin{array}{l}-0.2478 \\
(0.8385)\end{array}$ & $\begin{array}{l}-0.2019 \\
(0.1674)\end{array}$ \\
\hline $\operatorname{ar}(3)$ & $\begin{array}{c}1.9318^{* * * *} \\
(0.0584)\end{array}$ & $\begin{array}{l}-1.0844 \\
(0.7511)\end{array}$ & $\begin{array}{c}-0.7385^{* * *} * \\
(0.1482)\end{array}$ \\
\hline $\operatorname{ar}(4)$ & $\begin{array}{c}-0.3952 * * * \\
(0.0211)\end{array}$ & $\begin{array}{c}0.5387 * * \\
(0.2336)\end{array}$ & $\begin{array}{c}0.2787 * * * \\
(0.0525)\end{array}$ \\
\hline $\operatorname{ma}(1)$ & - & $\begin{array}{c}1.3724 * * * \\
(0.3220)\end{array}$ & $\begin{array}{c}5.6705^{* * *} \\
(0.1701)\end{array}$ \\
\hline $\operatorname{ma}(2)$ & - & $\begin{array}{c}0.7509 * * * \\
(0.1876)\end{array}$ & $\begin{array}{c}2.5139 * * * \\
(0.3717)\end{array}$ \\
\hline $\operatorname{ma}(3)$ & - & $\begin{array}{c}0.3967 * * * \\
(0.0967)\end{array}$ & $\begin{array}{c}1.0048^{* * * *} \\
(0.2951)\end{array}$ \\
\hline $\mathrm{ma}(4)$ & - & $\begin{array}{c}0.1440 * * * \\
(0.0469)\end{array}$ & - \\
\hline \multicolumn{4}{|c|}{ Variance equation } \\
\hline$\alpha 0$ & $\begin{array}{c}4.73 \mathrm{E}-10^{* * *} \\
(1.36 \mathrm{E}-10)\end{array}$ & $\begin{array}{c}2.96 \mathrm{E}-10^{* * *} * \\
(1.03 \mathrm{E}-10)\end{array}$ & $\begin{array}{c}4.50 \mathrm{E}-11 * * * \\
(5.90 \mathrm{E}-12)\end{array}$ \\
\hline$\alpha 1$ & $\begin{array}{c}0.0982 * * * \\
(0.0119)\end{array}$ & $\begin{array}{l}0.1003 * * * \\
(0.0158)\end{array}$ & $\begin{array}{c}0.4974 * * * \\
(0.0464)\end{array}$ \\
\hline$\beta 1$ & $\begin{array}{c}0.8852 * * * \\
(0.0138)\end{array}$ & $\begin{array}{c}0.8851 * * * \\
(0.0173)\end{array}$ & $\begin{array}{c}0.4736 * * * \\
(0.0332)\end{array}$ \\
\hline AIC value & -14.8724 & -15.2415 & -18.8491 \\
\hline Log likelihood & 14477.88 & 14841.94 & 18351.19 \\
\hline GED degree & 1.5206 & 1.5610 & 1.8540 \\
\hline
\end{tabular}

Note: The numbers in parentheses are Std. Errors of the estimates.

** Significance at 5\% level, *** significance at $1 \%$ level.

Table 4 shows that GED degree parameters of the three models are 1.5206, 1.5610 and 1.8540 respectively, both less than 2, confirming that the tails of the international oil returns are thicker than that of the standard normal distribution. GARCH term is significant at the level of $10 \%$, which indicates that the use of the $\operatorname{GARCH}(1,1)$ model is reasonable. The value of $\alpha_{1}+\beta_{1}$ is less than 1 , suggesting that each stock price time series satisfies the stable condition, and the conditional variance has long-term memory. This shows that the impact of external shocks is highly persistent both on large real estate companies and small real estate companies and on the volatility of the Shanghai Composite Index. In addition, the $\alpha_{1}$ value of large real estate companies and small real estate companies is larger than the corresponding value in the Shanghai Composite Index model, which indicates that, relatively speaking, the fluctuation of stock prices caused by external shocks outside the small real estate company's stock itself can make a quicker response.

\subsubsection{Asymmetric Effect of Stock Price Volatility}

The following examines the impact of favorable and unfavorable information on the cyclical fluctuations of different types of stock prices. This paper uses the TGARCH $(1,1)$ and EGARCH $(1$, 1) models to estimate the four time series and selects the better-fitting model in the TGARCH $(1,1)$ and EGARCH $(1,1)$ models. The empirical results are shown in Table 5. 
Table 5. Eparch, Starch Model Parameter Result

\begin{tabular}{|c|c|c|c|c|}
\hline & & dln_hplss & dln_hpsss & dln_hpzss \\
\hline \multicolumn{2}{|c|}{ Model } & TGARCH & TGARCH & EGARCH \\
\hline \multicolumn{2}{|c|}{$\alpha_{i}$} & 0.1150 & 0.7886 & 0.4459 \\
\hline \multicolumn{2}{|c|}{$\varphi_{i}$} & -0.0343 & -0.2956 & -0.0377 \\
\hline \multirow{2}{*}{ Leverage Effect } & Good News & 0.1150 & 0.7886 & 0.4082 \\
\hline & Bad News & 0.0807 & 0.4930 & 0.4836 \\
\hline
\end{tabular}

Table 5 shows that in the TGARCH and EGARCH models, the coefficients $\varphi$ of the asymmetric effect terms of the three time sequences significantly differ from zero, indicating that the fluctuations of the trend components of each series have asymmetric effects. Both don hapless and don hiss are well fitted by TGARCH and there are less than zero, meaning that for the trend components of these two series, "good news" can produce greater fluctuations than "bad news," i.e., there is a positive leverage effect. In terms of the degree of volatility, small companies see greater fluctuation in stock price returns than large companies, that is, when the "good news" appears in stocks of a small company, it will bring a 0.1150 shock to the stock price index, and when "bad news" occurs, it will bring a 0.0807 impact on the stock price index. The don hips fits well with EGARCH and its $\varphi$ is less than zero. The bad news generates stronger fluctuations than the same amount of good news, that is, there is a negative leverage effect. According to the estimated results of EGARCH and TGARCH models, the news impact curve is plotted in Fig. 1. We find that when the impact of information is greater than zero, that is, when the impact is positive, the curves of the don hapless and don hiss are both steep, while the negative impact is relatively gentle, which shows that the positive impact makes the periodic fluctuation more varied, the degree of volatility is in accordance with the TGARCH model. On the contrary, for don hips, when the impact of the news impact is less than zero, that is, the negative impact, the curve is steeper, indicating that the negative impact on the periodic fluctuation is greater.
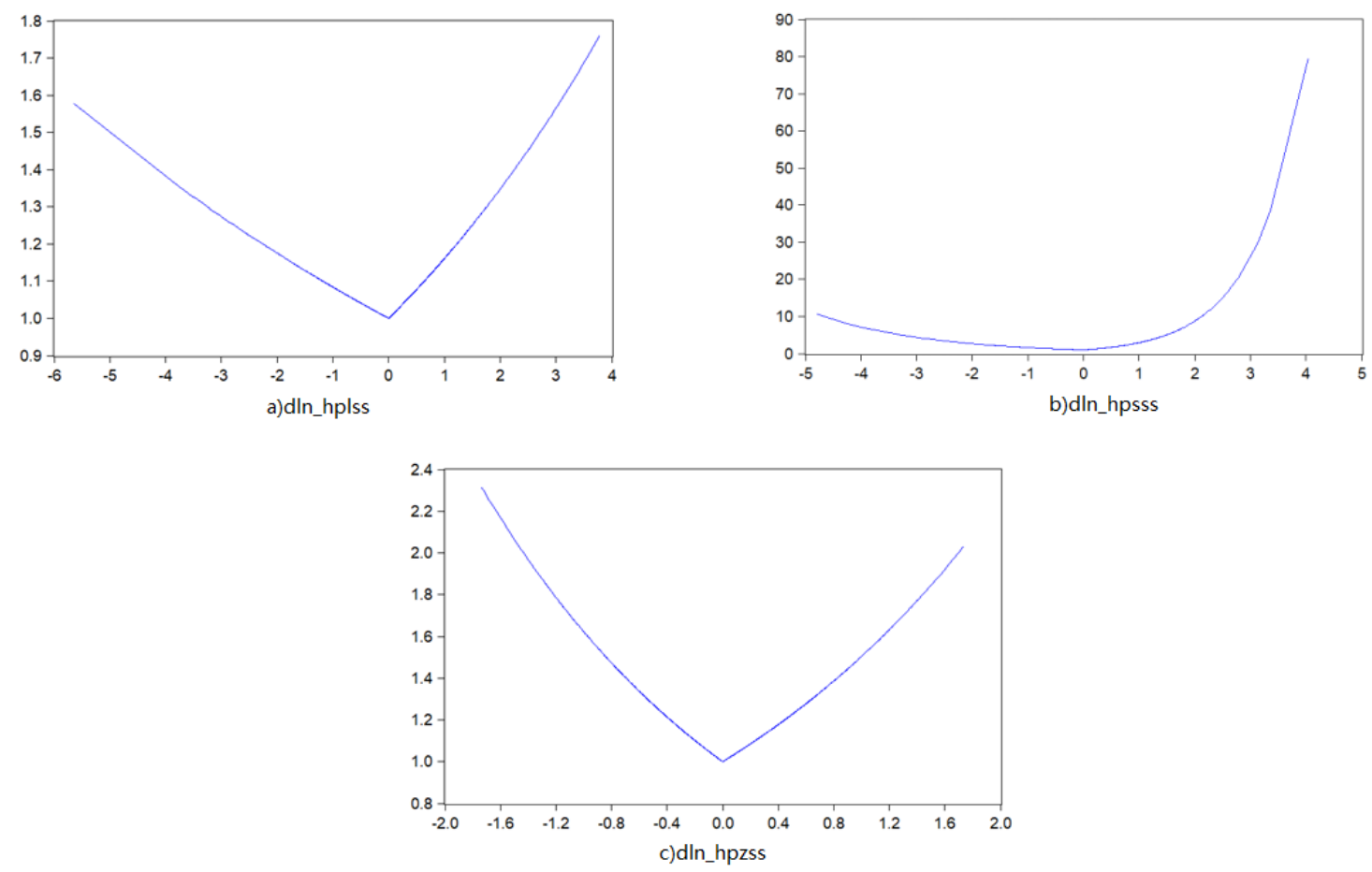

Fig 1. News Impact Curve 
Note: The horizontal line is the impact at time t-1, and the vertical line is the volatility at time t.

Generally, the bad news in the securities market has a greater impact than good news, which is reflected in the EGARCH model of the stock index's return on the Shanghai Stock Exchange Index. But in the real estate industry, good news generates more volatility than bad news. This finding can be attributed to investors' over-optimistic expectations toward the real estate market for the rapid development of China's real estate industry since 2010. When the bad news appears, investors continue to hold the majority of the real estate industry stock strategy, but when the good news emerges, it often leads to high investment enthusiasm for investors, which is particularly evident in smaller companies with speculative psychology.

\section{Main Conclusion}

This paper selects 102 real estate companies as the main research objects, and use the HP filter to de-trend the periodicity. Then, after taking into consideration of the great impact of heterogeneity of the company's scale on the stock price volatility, it classifies the trend component of HP's filtered stock price returns by ratio of market capitalization. Then the time series data of large and small real estate companies were obtained. On this basis, GARCH, TGARCH, and EGARCH models are used to empirically analyze the volatility of China's real estate industry's share price, and then compared then to the Shanghai Composite Index. The main findings are as follows.

First, price fluctuations of real estate companies with different scales have different characteristics. Large real estate companies and small real estate companies all have heterogeneity, volatility, and asymmetry. However, small real estate companies can respond quickly to the stock price fluctuations caused by external shocks outside the stock itself, which may be related to the operational flexibility of small real estate companies.

Second, there is a negative leverage effect on the stock price return of the Shanghai Stock Exchange Index. There are positive leverage effects on the series of stock price returns of the two types of real estate companies. Specifically speaking, as for stock price returns of the real estate industry, the impact of good news is greater than bad news. In terms of volatility, the fluctuation in the stock price return of small companies is greater than that of large companies. One of the possible reasons is investors' over-optimistic expectations of the real estate market for the rapid development of China's real estate industry since 2010 . When the bad news appears, investors continue to hold the majority of the real estate industry stock strategy, but when the good news emerges, it often leads to high investment enthusiasm for investors. This precisely reflects the particularity of the real estate industry in China.

\section{Acknowledgements}

This work is supported by the Hunan Provincial Natural Science Foundation of China (Grant no. 2017JJ3024).

\section{References}

[1]. Engle R. Autoregressive Conditional Heteroskedasticity with Estimates of the Variance of UK Inflation [J]. Econometrical, 1982, 50(4):987-1008

[2]. Bollerslev T. Generalized Autoregressive Conditional Heteroskedasticiy [J]. Journal of Econometrics, 1986, 31 (3):307-327.

[3]. Zairian J.M. Threshold Heteroskedstic Models [J]. Journal of Economic Dynamics and Control, Manuscript, 1994, 18 (5):931-955

[4]. Hedrick R J, Prescott E C .Post-war US business cycles: an empirical investigation [J] .J Money, Credit and Banking, 1997, 29(1):1-16. 
[5]. Lu Xiaoping. A Comparative Study of the Characteristics of Stock Price Fluctuations in Commercial Banks [J].Economic Forum, 2017 (6):87-90.

[6]. Jiang Xiangcheng, Xing Yasmin. Study on the Volatility of China's Stock Market Based on GARCH Model [J].Journal of Southwest China Normal University (Natural Science Edition), 2017, 42(2):115-119.

[7]. Chen Minho, Feng Yan. An Empirical Study on the Volatility of Stock Prices in the Automotive Industry--Based on the GARCH Model[J].Contemporary Economics, 2010 (3):114-116.

[8]. Su Gong, Ma Bo. Model Verification of Stock Price Volatility in IT Industry [J].Statistics and Decision, 2007 (4):96-99.

[9]. Chen Fungi, Wang Rung. Research on Financial Security of Real Estate Industry [J].Communication of Finance and Accounting, 2017(14):79-81.

[10]. Cao Guangxi, Yoyo. An Empirical Study on the Dynamic Correlation of Dynamic Spill over Effects and Dynamic Correlation between Shanghai and Shenzhen Stock Markets--Based on Long Memory Vary- Beck (DC)-March (1,1) Model[J]. Systems Engineering, 2008 (05):47-54.

[11]. Jiang Xiangtan, Wang Li, Zhu Tao. Vector Financial Time Series Co-integration and Collaborative Sustained Relationship: Based on Theoretical Consideration [J].Journal of Industrial Engineering and Engineering Management, 2008 (1):78-81.

[12]. Liang Nina. Study of Asymmetry on Stock Volatility in China's Shanghai Stock Market Based on GARCH Family Model[J].Times Finance, 2016(21):154.

[13]. Chen Cong. Research on Stock Price Fluctuation Based on Arch Model[D].Lanzhou University,2015

[14]. Shan Tong. Research on the Volatility of China's Stock Price Based on Arch Model [D]. Donoghue University, 2015

[15]. Yu Haiphong. Analysis and Risk Measurement of Stock Market Volatility Based on Arch Model [D].Jilin University,2015. 